\title{
Rhinophototherapy: gimmick or an emerging treatment option for allergic rhinitis?*
}

\author{
S.C. Leong
}

Department of Otorhinolaryngology, Head and Neck Surgery, Royal Liverpool University Hospital, Liverpool, United Kingdom

SUMMARY Photodynamic therapy has been used in treating immune-mediated dermatological conditions such as psoriasis and atopic dermatitis. There are emerging reports on the efficacy of intranasal phototherapy in allergic rhinitis. The aim of this review was to assess intranasal phototherapy in the treatment of allergic rhinitis, with particular emphasis on clinical efficacy, scientific basis and safety. A structured search of the U.S. National Library of Medicine (PubMed), the Cochrane Collaboration library, Google Scholar and ISI Web of Knowledge database was undertaken using MeSH terms 'phototherapy' and 'rhinitis.' Fourteen full-text articles were available for review. Three different phototherapy medical devices were assessed: (1) Bionase ${ }^{\mathrm{TM}}$, (2) Allergy Reliever SN206 and (3) Rhinolight ${ }^{\circledR}$. Light wavelength used in these devices ranged from red light to ultraviolet. Clinical use of intranasal phototherapy appears to be safe and well tolerated. Most studies demonstrated symptomatic improvement and quality of life scores. No improvement in objective measures of nasal airflow was demonstrated. Beneficial effects of phototherapy on inflammatory markers remain equivocal. Phototherapy treatment results in DNA damage but does not appear to predispose to carcinogenesis. However, long-term prospective studies are required to verify this. The quality of published studies was variable and thus the strength of recommending intranasal phototherapy is currently weak.

Key words: phototherapy, rhinitis, allergy, light, complementary therapies

\section{INTRODUCTION}

Despite the skepticism, controversy and lack of evidence, patients often turn to complementary - alternative medicines (CAMs) when conventional treatment is ineffective. It has been estimated that up to $50 \%$ of adults currently use or have used complementary and alternative medicines (CAMs) on at least one occasion to treat allergic rhinitis ${ }^{(1)}$. The market in Britain alone is believed to be worth approximately $£ 210 \mathrm{~m}$ ( $€ 244 \mathrm{~m}$, $\$ 327 \mathrm{~m}$ ), with one in five adults thought to be consumers, and some treatments (particularly homeopathy) available from the National Health Service ${ }^{(2)}$. The evidence available suggests that many people are drawn to the use of CAMs because it allows them to take responsibility in the management of their problem and to explore therapies that are regarded as traditional medicine in some countries. A variety of CAMs are in common use including acupuncture, homeopathy and Chinese herbal medicines ${ }^{(3)}$.

Phototherapy with ultraviolet (UV) light has been used in treating immune-mediated dermatological conditions such as psoriasis and atopic dermatitis. The therapeutic mechanism of UV light includes reduction of antigen presentation by dendritic cells, inhibition of pro-inflammatory cytokine synthesis and release, and induction of apoptosis in immune cells (4). Intranasal phototherapy is an emerging treatment modality for allergic rhinitis. Given that phototherapy is established treatment for many dermatologic conditions, it is possible that phototherapy may have a role in rhinology. The aim of this review was to assess intranasal phototherapy in the treatment of allergic rhinitis, with particular emphasis on clinical efficacy, scientific basis and safety.

\section{SEARCH METHODOLOGY}

A structured search of the U.S. National Library of Medicine (PubMed), the Cochrane Collaboration library, Google Scholar and ISI Web of Knowledge database was undertaken using MeSH terms 'phototherapy' and 'rhinitis'. The literature review period was set from 1 January, 1995 to 30 April, 2011 and limited to English-language articles only. Correspondence letters and conference abstracts were excluded, as were citations published without an abstract. Each abstract was then screened for relevance and the full-text article obtained. Where 
the full-text article was not available electronically or within university hospital library holdings, an attempt was made to contact the correspondence author via email to obtain the article.

Only studies reporting the use of intranasal phototherapy were eligible for inclusion. The bibliography of each article was reviewed to identify any other potentially relevant studies. Where appropriate, the quality of clinical trials was assessed by using the scale developed and validated by Jadad et al., ${ }^{(5)}$. This scoring system takes into account the most relevant characteristics of a clinical trial, which are randomization and blinding. Two points are given, respectively, to correct random allocation and to correct blinding, and 1 point is given if description of dropouts and withdrawals is provided. Thus the maximum score is 5 , and a score of at least 3 indicates an adequate methodology. The strength of the evidence of the studies was then evaluated by using the recommendations by Shekelle et al., ${ }^{(6)}$ (Table 2).

\section{RESULTS}

The PubMed review identified 31 citations, of which eight were not in English language. Of the remaining 23 citations, 13 were deemed relevant after reviewing the abstracts. Two other studies were identified from the bibliography, which was suitable for inclusion. Two studies were excluded; one evaluating the clinical outcome of far-infrared light extra-nasally in subjects with allergic rhinitis ${ }^{(7)}$, and the other irradiated (660 $\mathrm{nm}$ and $850 \mathrm{~nm}$ ) the acupuncture point Shangyingxiang Xue on the face adjacent to the nose to treat allergic rhinitis ${ }^{(8)}$. No other relevant studies were identified from the other electronic databases. A Cochrane protocol was registered in July 2009 but no review has been issued ${ }^{(9)}$. One abstract was deemed suitable for inclusion but the full-text article was not available for review ${ }^{(10)}$.

In all, fourteen full-text articles were available for review. The type of studies varied widely as were quality. The quality of the clinical trials ranged from Jadad score 0 to 5 (Table 3 ). Of the three prospective, randomized, placebo-controlled, double-blind studies reviewed, only one had power calculation for sample size. There was one prospective, randomized, placebo-controlled, single-blind study and one prospective, randomized, un-blinded study. There were four open-label prospective pilot studies involving small study cohorts of less than 20 subjects. There was a larger prospective unrandomised study assessing quality of life issues involving 100 subjects. The remaining articles were two reviews and two observational studies of histological changes after phototherapy.

Three different phototherapy medical devices were assessed: (1) Bionase ${ }^{\mathrm{TM}}$, (2) Allergy Reliever SN206 and (3) Rhinolight ${ }^{\circledR}$. None of the studies compared one device with the other. Each device utilized a unique frequency within the light spectrum ranging from ultra-violet to red color light. Treatment regime varied between each product. Both the Bionase ${ }^{\mathrm{TM}}$ and Allergy Reliever SN206 are small pocket size devices consisting of an intranasal portion connected to a battery operated light source. Operation is straightforward with a single on-off switch on the light source unit. The device switches off automatically after a pre-set treatment period. Conversely, the Rhinolight ${ }^{\circledR}$ is a desktop device that requires electrical power supply. It is connected to a hand piece, which houses the emitting light. The duration and dose of treatment can be controlled from the touch-screen control panel on the desktop portion.

Meta-analysis of the results was not possible given the heterogeneity of the studies and devices used. Further discussion is detailed below according to the individual intranasal phototherapy device used.

\section{Bionase $^{\mathrm{TM}}$}

Bionase $^{\mathrm{TM}}$ is a patented medical device (Figure 1) manufactured by Syro Technologies Ltd. (Jaffa, Israel). This device emits a visible red light at a single wavelength of $660 \pm 5 \mathrm{~nm}$.

Table 1. Scoring system of trials according to Jadad et al. ${ }^{(5)}$.

\begin{tabular}{llll}
\hline Question & & Score \\
\hline 1 & $\begin{array}{l}\text { Study described as randomized (including the words "random", } \\
\text { randomization", "randomly")? }\end{array}$ & Yes $=1$ & No $=0$ \\
2 & Study described as double-blind? & Yes $=1$ & No $=0$ \\
3 & Withdrawals and dropouts described? & Yes $=1$ & No $=0$ \\
4 & Method of randomization described and appropriate? & Yes $=1$ & No $=0$ \\
5 & Method of double-blinding described and appropriate? & Yes $=1$ & No $=0$ \\
\hline
\end{tabular}

Table 2. Strength of recommendation according to Shekelle et al. ${ }^{\left({ }^{6}\right)}$.

\begin{tabular}{|c|c|c|c|}
\hline \multicolumn{2}{|c|}{ Category of evidence } & \multicolumn{2}{|c|}{ Strength of recommendation } \\
\hline $\mathrm{Ia}$ & Meta-analysis of randomized controlled trials & A & Directly based on category I \\
\hline $\mathrm{Ib}$ & At least 1 randomized controlled trial & & \\
\hline IIa & At least 1 controlled trial without randomization & B & Directly based on category II or extrapolated from category I \\
\hline $\mathrm{IIb}$ & At least 1 type of quasiexperimental study & & \\
\hline III & Nonexperimental descriptive studies & $\mathrm{C}$ & Directly based on category III or extrapolated from category I - II \\
\hline IV & Expert opinions or committee reports & $\mathrm{D}$ & Directly based on category IV or extrapolated from category I - III \\
\hline
\end{tabular}


Table 3. Summary of intranasal phototherapy clinical studies in descending order of Jadad score. (ECP = eosinophil cationic proteins, PIFn - nasal peak inspiratory flow, PEFn = nasal peak expiratory flow, UV = ultraviolet, QoL $=$ quality of life, NOSE $=$ nasal obstruction symptom evaluation).

\begin{tabular}{|c|c|c|c|c|c|}
\hline $\begin{array}{l}\text { First author } \\
\text { (year) }\end{array}$ & Treatment & Control & No. of patients & Jadad score & Main results \\
\hline $\begin{array}{l}\text { Emberlin } \\
(2009)\end{array}$ & $\begin{array}{l}\text { Allergy Reliever SN206 } \\
\text { (652nm, 940nm light) }\end{array}$ & Placebo & $\begin{array}{c}112 \\
(101)\end{array}$ & 5 & $\begin{array}{l}\text { Improved symptom scores (sneezing, rhinorrhoea, } \\
\text { epiphora, itchy mouth/palate). No significant } \\
\text { differences in ECPs, PIFn, PEFn. }\end{array}$ \\
\hline $\begin{array}{l}\text { Koreck } \\
(2005)\end{array}$ & $\begin{array}{l}\text { Rhinolight }^{\circledR} \text { (UV-A, } \\
\text { UV-B, visible light) }\end{array}$ & Placebo & $\begin{array}{c}49 \\
(49)\end{array}$ & 4 & $\begin{array}{l}\text { Improved symptom scores (sneezing, rhinorrhoea, } \\
\text { nasal itching). Reduction in eosinophils, ECPs, } \\
\text { IL-5 in nasal lavage. No improvement in acoustic } \\
\text { rhinometry. }\end{array}$ \\
\hline Neuman (1997) & $\begin{array}{l}\text { Bionase }^{\mathrm{TM}} \text { (intranasal } \\
\text { red light) }\end{array}$ & Placebo & $\begin{array}{c}79 \\
(79)\end{array}$ & 2 & $\begin{array}{l}\text { Improved symptom scores (obstruction, rhinor- } \\
\text { rhoea) and endoscopic findings (mucosal conges- } \\
\text { tion, secretions) }\end{array}$ \\
\hline $\begin{array}{l}\text { Cingi } \\
(2010)\end{array}$ & Rhinolight $^{\circledR}$ & Placebo & $\begin{array}{c}79 \\
(79)\end{array}$ & 2 & $\begin{array}{l}\text { Significantly greater improvement in nasal } \\
\text { symptom scores than placebo cohort. }\end{array}$ \\
\hline $\begin{array}{l}\text { Garaczi } \\
(2011)\end{array}$ & Rhinolight $^{\circledR}$ & Nil & $\begin{array}{c}31 \\
(31)\end{array}$ & 2 & $\begin{array}{l}\text { Rhinolight } t^{\circledR}(n=18) \text { compared with oral fexofena- } \\
\text { dine }(n=13) \text {. No significant differences were found } \\
\text { in the symptom scores between the cohorts. }\end{array}$ \\
\hline $\begin{array}{l}\text { Csoma } \\
(2004)\end{array}$ & $\begin{array}{l}\text { Xenon Chloride laser } \\
\quad(308 \mathrm{~nm})\end{array}$ & Nil & $\begin{array}{c}15 \\
(11)\end{array}$ & 0 & $\begin{array}{l}\text { Two study cohorts: low dose Xenon Chlore }(\mathrm{XeCl}) \text {, } \\
\text { medium dose } \mathrm{XeCl} \text {. Improvement symptoms scores } \\
\text { with medium dose only. }\end{array}$ \\
\hline $\begin{array}{l}\text { Csoma } \\
(2006)\end{array}$ & $\begin{array}{l}\text { Psoraren - UVA } \\
\quad(365 \mathrm{~nm})\end{array}$ & Nil & $\begin{array}{c}17 \\
(13)\end{array}$ & 0 & Improved symptom scores. \\
\hline $\begin{array}{l}\text { Cingi } \\
(2009)\end{array}$ & Rhinolight $^{\circledR}$ & Nil & $\begin{array}{l}100 \\
(?)\end{array}$ & 0 & Improved nasal symptom and quality of life scores. \\
\hline $\begin{array}{l}\text { Bella } \\
(2010)\end{array}$ & UVB & Nil & $\begin{array}{c}13 \\
(10)\end{array}$ & 0 & $\begin{array}{l}\text { All patients have nasal polyps (Grade I- III). } \\
\text { Improved QoL scores (NOSE) and nasal } \\
\text { obstruction. }\end{array}$ \\
\hline
\end{tabular}

The manufacturer's website (www.biolight.co.il) recommended starting treatment three times daily and then titrated according to symptomatic response. Each treatment session lasts for 4.5 minutes and the device switches off automatically. The device is recommended by the manufacturer to be suitable from the age of four years.

To date, only one study has been published evaluating the efficacy of Bionase ${ }^{\mathrm{TM}}$ in treating perennial allergic rhinitis and nasal polyposis ${ }^{(11)}$. In a double-blind randomized prospective study, 50 subjects with perennial allergic rhinitis and 10 with nasal polyposis received treatment three times a day for 14 days. Power calculation and randomization was not described in any detail. The control group, consisting of 29 subjects with allergic rhinitis and 1 with nasal polyposis, was treated with a sham illumination as placebo. All subjects were selected after positive skin prick test to perennial inhalant allergens, defined as a wheal of $3 \mathrm{~mm}$ or greater with erythema of at least $5 \mathrm{~mm}$. After recording their symptoms in a diary for two weeks as a run-in period, all suitable candidates were reassessed and underwent endoscopic examination. Recorded endoscopic examination before and after phototherapy was reviewed by an ENT specialist who, blinded to the treatment received, assessed changes in nasal obstruction, rhinitis and oedema of the middle turbinate.

The main pretreatment sinonasal complaints were obstruction and rhinorrhoea, where between $79 \%-94 \%$ of the study cohort reported moderate or severe symptoms. Between $76 \%$
- $100 \%$ complaint of none or mild symptoms of itching, headache and postnasal drip. Mild overall improvement of symptoms was experienced by $44 \%$ and marked improvement by $29 \%$ of subjects in the treatment group. Nasal obstruction and rhinorrhoea were the most common symptoms to experience marked improvement, whilst improvement in nasal itching, headache and postnasal drip was largely mild. Subjects with concomitant septal deviation reported smaller degree of improvement and the majority of those with nasal polyps reported no change. Using the chi square test, the authors reported that endoscopic findings in the treatment group were statistically better compared to controls. Improvement in mucosal congestion, amount of secretions and middle turbinate oedema was noted in $61 \%, 65 \%$ and $48 \%$ respectively compared to $21 \%, 7 \%$ and $12 \%$ respectively in the control group. No endoscopic improvement was noted in patients with nasal polyposis.

\section{Allergy Reliever SN206}

The Allergy Reliever SN206 (Lloyds Pharmacy Ltd., Coventry, U.K.; Figure 2) emits infrared light delivering 0.54 joules $/ \mathrm{cm}^{2}$ per three-minute cycle. The manufacturer claims that the 652 $\mathrm{nm}$ and $940 \mathrm{~nm}$ infrared light delivered via the nasal probes suppresses release of histamine promotes and increased blood flow respectively (www.lloydspharmacy.com/allergy-reliever). This device has been marketed for several years and an estimated 50,000 units were sold before being assessed in one clinical trial. 
Emberlin and Lewis conducted a randomized placebo-controlled double-blind study on adult subjects suffering with hay fever ${ }^{(12)}$. The study was conducted out of pollen season and involved grass pollen challenge after a two-week period of treatment (active and placebo). Power calculation was performed for sample size and subjects were assigned to either active or placebo treatment by stratified random sample based on age, gender and severity of reported symptoms. Potential volunteers were recruited by questionnaire interview focusing on the presence of hay fever in the preceding two years, severity of sinonasal symptoms and treatment received. All suitable subjects had a reported positive skin prick test for grass although those who professed to having had the test within two years of the study were not verified by the investigators.

Subjects who fulfilled the inclusion criteria were instructed to use device for three minutes, three times daily for 14 day. Both subjective and objective variables were assessed prior to and at fixed intervals after allergen challenge. The quantity of grass pollen (Dactylis glomerata), delivered to the nostrils with a micro-spoon, was equivalent to the allergen load on a high pollen count day (350 grains pollen per cubic meter air). Sinonasal symptoms were scored on a five-point Linkert scale $(0=$ absent, $5=$ very severe $)$. Nasal secretions were taken for eosinophil cationic proteins (ECP) analysis using a strip of filter paper. Sneezing, rhinorrhoea, epiphora and ECP were defined by primary outcome measures. Furthermore, nasal peak inspiratory flow (PIFn) and nasal peak expiratory flow (PEFn) were recorded as secondary outcome measures, as were ocular symptoms (epihora, itchiness).

Of the 112 subjects recruited, 101 completed the trial. Prior to pollen challenge, the baseline average symptom scores for the placebo group were higher than those in the treatment group. The highest symptoms scores were for sneezing and rhinorrhoea and lowest score for ocular symptoms. Mean symptom scores for sneezing, rhinorrhoea, itchy palate and epiphora rose peaking within 15 minutes after pollen challenge and waned gradually thereafter. These subjective variables were observed to be significantly greater in the placebo group but the difference between the two cohorts narrowed over time. Only rhinorrhoea was observed to be significantly worse in the placebo group at the end of the study, 250 minutes after pollen challenge. There were no significant differences in the results for the ECP concentrations, PIFn and PEFn between the two groups at baseline and after pollen challenge or when comparing the individual results between the two groups at specific sample times.

\section{Rhinolight $^{\circledR}$}

The Rhinolight ${ }^{\circledR}$ (Figure 3 ) is a patented device manufactured by Rhinolight Ltd., which is based in Szeged, Hungary. This company started operations in 2003 and claims to have treated 20,000 patients with the phototherapy device (www.rhinolight. hu/language/en). Rhinolight ${ }^{\circledR}$ emits a composite light, consisting of $70 \%$ visible light, $25 \%$ UV-A and 5\% UV-B. Rhinolight ${ }^{\circledR}$ is recommended for the treatment of both perennial and seasonal allergic rhinitis; each condition having different treatment regimes and dose escalation schedules.

Koreck et al., ${ }^{(13)}$ randomized 49 volunteers suffering with seasonal allergic rhinitis to receive either Rhinolight ${ }^{\circledR}$ (25 subjects) or low-intensity visible light housed within the Rhinolight ${ }^{\circledR}$ device. Each nasal cavity was irradiated three times a week for three weeks with increasing doses of either Rhinolight ${ }^{\circledR}$ (starting dose $1.6 \mathrm{~J} / \mathrm{cm}^{2}$ ) or visible light (starting dose $0.06 \mathrm{~J} /$ $\mathrm{cm}^{2}$ ). The dose was increased by $0.25 \mathrm{~J} / \mathrm{cm}^{2}$ every third treatment day. Subjects were allowed to use oral Cetirizine as rescue medication during the three-week study period. Each subject kept a diary of daily symptoms, specifically on nasal obstruction, nasal itching, rhinorrhoea and sneezing. A fourpoint Linkert scale $(0=$ no symptoms, $4=$ severe $)$ was used to calculate the Total Nasal Symptom Score (TNSS). Subjects were assessed weekly by an independent investigator who also performed acoustic rhinometry and nasal lavage. The nasal lavage was analysed for cytokines (IL-4, IL-5 and IL-10) and ECP concentration.

The TNSS decreased significantly in the treatment cohort, for sneezing, rhinorrhoea and nasal itching. No improvement in symptoms scores was observed in the control cohort. No improvement was recorded with acoustic rhinometry in either group. The authors reported that the percentage of eosinophils, ECP and IL-5 levels decreased significantly after Rhinolight ${ }^{\circledR}$, whereas these variables increased in the control group. The decrease in IL-4 levels in the treatment cohort did not achieve statistical significance.

The subjective improvement in sinonasal symptoms was also observed by Cingi et al., ${ }^{(14)}$ who prospectively studied a cohort of 100 patient using the Rhinoconjunctivitis Quality of Life Questionnaire (RQLQ) and TNSS. Patients were not on any treatment for allergic rhinitis at the start of the study and no rescue medication was permitted. Assessments were performed at baseline, at one month and at three months after Rhinolight ${ }^{\circledR}$ treatment.

The RQLQ consist of 28 questions, grouped in seven domains; sleep, non-nasal eye symptoms, practical problems, nasal symptoms, eye symptoms, activities limited by nose or eye symptoms and emotional function. The authors reported that the each RQLQ domain scores improved following treatment and remained statistically significant at three months followup compared to baseline.

The same research group also conducted a prospective, randomized, single-blind, placebo-controlled trial in patients with persistent allergic rhinitis ${ }^{(15)}$. Similarly, the TNSS was used as the outcome measure although follow-up was limited to one month after treatment. Seventy-nine patients were randomly assigned using computer-generated randomization: 41 in the Rhinolight ${ }^{\circledR}$ and 38 in the placebo group who received low- 


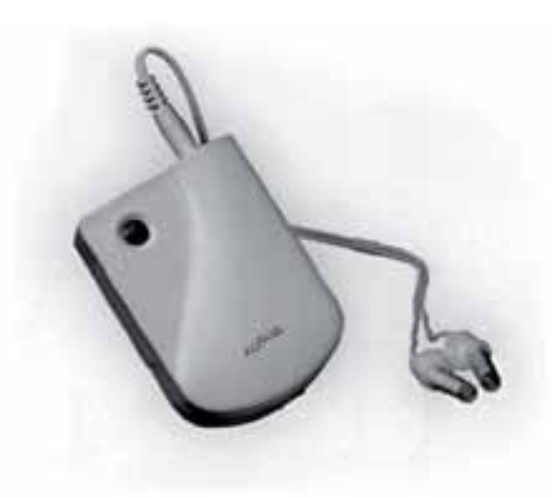

Figure 1. The Bionase phototherapy device.

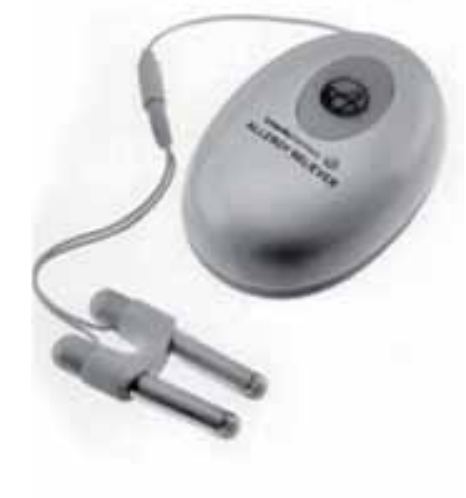

Figure 2. The Allergy Reliever SN206 phototherapy device.

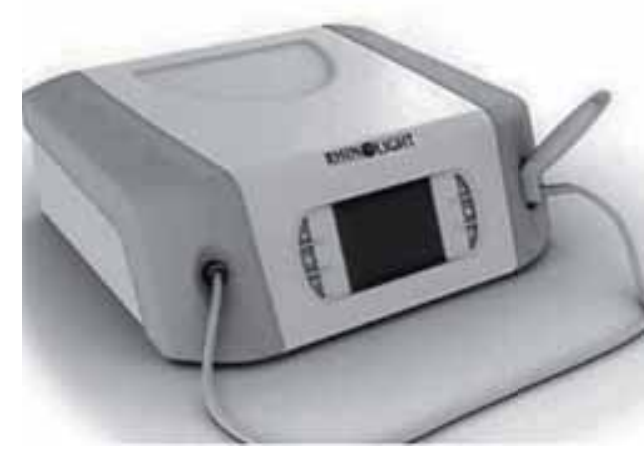

Figure 3. The Rhinolight device with the intranasal portion docked into the desktop unit. intensity visible light. The TNSS scores decreased significantly in both groups although the decrease in symptom scores was greater in the active treatment cohort. The authors concluded that Rhinolight ${ }^{\circledR}$ treatment was more effective than low-intensity visible light.

Garaczi et al., (16) compared the clinical effectiveness of Rhinolight ${ }^{\circledR}$ with oral fexofenadine hydrochloride in a cohort of 31 subjects suffering with ragweed-induced allergic rhinitis. The study was conducted during pollen season and suitable subjects were enrolled after positive skin-prick test and an elevated level of ragweed-specific Ig-E antibody. The study cohort was randomly assigned to either receive intranasal Rhinolight ${ }^{\circledR}$ or $180 \mathrm{mg}$ fexofenadine hydrochloride daily. Assessments were performed at day-1, day-7 and day-14 after commencement of treatment. The authors reported that the scores for each TNSS parameter decreased significantly compared to day-1, whereas only sneezing was reported to be significantly improved in the fexofenadine cohort. However when both treatment groups were compared, no significant differences were found in the symptom scores although the authors noted that the improvement was more pronounced following Rhinolight ${ }^{\circledR}$ treatment. Over half of patients (61.1\%) reported at least 50\% improvement in the TNSS compared to $15.4 \%$ in the fexofenadine group.

The Szeged-based research group also conducted a number of pilot studies using the Rhinolight ${ }^{\circledR}$ device to deliver other light wavelengths to treat allergic rhinitis and nasal polyps. A xenon chloride $(\mathrm{XeCl})$ ultraviolet $\mathrm{B}(\mathrm{UV}-\mathrm{B})$ laser was evaluated in a study comparing low-dose $(\mathrm{n}=10)$ versus medium-dose treatment $(\mathrm{n}=8)^{(17)}$. All patients who were treatment with medium-dose $\mathrm{XeCl}$ laser reported improved symptoms (rhinorrhoea, sneezing and obstruction). Expectantly, there was no improvement in TNSS reported by the low-dose cohort. Intranasal psoralen UV-A (PUVA) therapy has also demon- strated symptomatic improvement and clinical tolerability in the treatment of seasonal allergic rhinitis ${ }^{(18)}$. In this study, 13 of the enrolled 17 patients completed the three-week treatment course reported greater improvement in sneezing and rhinorrhoea than itching or obstruction. Narrow-band UV-B light (NB-UVB) has been evaluated in patients with varying severity of bilateral nasal polyposis (Grade $1-3)^{(19)}$. Treatment lasted 12 weeks in incremental doses of NB-UVB $(300-1200 \mathrm{~mJ} /$ $\mathrm{cm}^{2}$ ). The results are difficult to interpret. Despite reporting improvement in average symptom and quality of life scores at one and three months after treatment, a third of the cohort required topical steroids at the first follow-up. The authors also reported that endoscopic changes paralleled improvement in symptom scores although details were not presented in the paper.

\section{Side effects of intranasal phototherapy}

Clinical use of intranasal phototherapy appears to be safe and well tolerated. No adverse events were reported following the use of Bionase ${ }^{\mathrm{TM}}$ and Allergy Reliever SN206 ${ }^{(11,12)}$. The most common side effect reported following Rhinolight ${ }^{\circledR}$ was mild dryness in the nasal cavity which was attenuated with the application of an emollient ${ }^{(20)}$. Severe dryness was reported in only one subject necessitating cessation of treatment ${ }^{(13)}$. However, long-term side effects from regular intranasal treatment are unknown as all studies were concluded after one treatment course.

\section{Effects of intranasal phototherapy on nasal mucosa}

Studies on the effect of phototherapy on nasal mucosa have only been reported for Rhinolight ${ }^{\circledR}$. Koreck et al., ${ }^{(21)}$ collected nasal cytology with a Rhino-probe curette from eight volunteers with rag-weed allergy before the start of Rhinolight ${ }^{\circledR}$ therapy, immediately after last treatment, 10 days and two months after last treatment. The tissue samples were subjected to single cell gel electrophoresis for endonuclease to detect DNA dam- 
age and also stained with cyclobutane pyrimidine dimer (CPD) monoclonal antibodies. CPDs are used for the detection and quantification of DNA damage from UV light irradiation. Nasal mucosa from the inferior turbinate of patients undergoing turbinate resection surgery was used as control. Significant DNA damage was observed immediately after completing two weeks treatment of Rhinolight ${ }^{\circledR}$ which reduced at the day-10 assessment. At two months follow-up, the level of DNA damage was reported to be identical to baseline and control group. No CPDs were detected at baseline and at 2 months follow-up, although elevated levels were present immediately after phototherapy treatment, which decreased significantly 10 days later.

In a small study cohort of 10 subjects, Brehmer and Schön (22) reported that whilst subjective symptoms scores improved, no biological effect was observed in nasal Langerhans cells following Rhinolight ${ }^{\circledR}$ treatment. Nasal mucosa biopsies from the inferior turbinate were obtained under local anaesthesia for histological and immunohistochemistry analysis. The CD1a protein mediates the presentation of primarily lipid and glycolipid antigens to $\mathrm{T}$ cells. CD3 is part of the $\mathrm{T}$ cell receptor complex on a mature $\mathrm{T}$ lymphocyte whilst $\mathrm{CD} 4$ is a glycoprotein expressed on the surface of $\mathrm{T}$ helper cells, regulatory $\mathrm{T}$ cells, monocytes, macrophages, and dendritic cells. CD8 is a transmembrane glycoprotein that serves as a coreceptor for the $\mathrm{T}$ cell receptor and is a marker for cytotoxic $\mathrm{T}$ cells. Mucosal vascularisation, as a marker of inflammatory changes, was assessed using a CD31-directed monoclonal antibody. Examination under light microscopy of mucosal samples stained with haematoxylin and eosin showed no significant histological differences. Levels of monoclonal antibiodies to CD1a, CD3, CD4, CD8 and CD31 showed no significant difference between pre and post treatment samples.

The two major photoproducts induced in DNA by UVB occur at sites of adjacent pyramidine bases and include the cyclobutane pyrimidine dimer (CPD) and pyrimidine-pyrimidone (6-4) dimer (6-4 PD). These dimers are believed to be the products of premutagenic events responsible for the initiation of carcinogenesis. Radioimmunoassay was used to quantify these photoproducts in DNA purified from nasal mucosa samples from subjects treated with Rhinolight ${ }^{\circledR}{ }^{(23)}$. The authors reported that both CPD and 6-4 PD levels were significantly raised immediately after a single exposure to Rhinolight ${ }^{\circledR}$ for three minutes and gradually decreased at specific follow-up time points $(24,48$ and 72 hours after completion of treatment). Levels of these photoproducts gradually fell and were near baseline levels 72 hours after treatment. However, some caution must be exercised when interpreting these results as final analysis was obtained from only 10 patients compared to 30 subjects who started the trial. Furthermore, of the 30 original patients, the same patients were not necessarily available for tissue collection at all of the various follow-up time points. A similar trend was also observed when patients were exposed to the full three-week treatment course. Although the level of CPDs varied widely between the subjects, the average concentration returned to baseline one week after completion of treatment and remained unchanged two months after the final treatment course.

\section{DISCUSSION}

Intranasal phototherapy has been available commercially for the past decade. Market penetration of these products remains variable depending on prevailing legislation of medical devices in individual countries. Both the Bionase ${ }^{\mathrm{TM}}$ and Allergy Reliever SN206 are consumer products, whilst the Rhinolight ${ }^{\circledR}$ is likely available at specialist clinics. Over 10,000 patients have been treated with the Rhinolight ${ }^{\circledR}$ in 19 countries mainly in Central and Eastern Europe, and the Far East ${ }^{(20)}$. In excess of 50,000 units of the Allergy Reliever SN206 have been sold ${ }^{(12)}$.

The justification for using phototherapy in the treatment of allergic rhinitis is largely based on inferred benefit from wellestablished practices in dermatology. For example, high dose red light phototherapy may induce inhibition or destruction of sebaceous glands, resulting in clinical improvement in the treatment of acne vulgaris ${ }^{(24,25)}$. Higher intensity light (632.8 $\mathrm{nm}, 100 \mathrm{~J} / \mathrm{cm}^{2}$ at $100 \mathrm{~W}$ ) has also been shown to be effective in the treatment of genital warts ${ }^{(26)}$. The mechanism of action is complex; red to near infrared light is thought to be absorbed by mitochondrial respiratory chain components, resulting in the increase of reactive oxygen species, and adenosine triphosphate (ATP)/or cyclic AMP, and initiating a signaling cascade which promotes cellular proliferation and cytoprotection ${ }^{(27)}$. However, scientific evidence to support these immune-modulating effects in the nose has not been studied in any great detail. In fact, it remains to be answered whether an effect exists at all. Eosinophil cationic proteins (ECPs) are released during degranulation of eosinophils and are involved in neurotoxic and ribonucleo-lytic processes during inflammatory reactions. Raised levels of ECPs have been recorded in acute exacerbation of asthma, psoriasis and dermatitis. No significant change in levels between baseline and after phototherapy treatment was noted ${ }^{(12)}$. Given the lower treatment dose than that normally used on the skin, it can be assumed that effect of red light therapy in the nose would be minimal.

The available evidence that Rhinolight ${ }^{\circledR}$ phototherapy has an immune-modulating effect on nasal mucosa is conflicting. The number of eosinophils, and the level of ECP and IL-5 from nasal lavage decreased significantly after Rhinolight ${ }^{\circledR}$ treatment (13). Furthermore, in vitro irradiation of T-lymphocytes and eosinophils with Rhinolight ${ }^{\circledR}$ induced apoptosis and decreased b-hexosaminidase release. The numbers of Langerhans cells increases after allergen challenge and exposure, and possess high-affinity receptors for Ig-E. These cells are responsible not only for the initial sensitization and Ig-E synthesis by B cells, but also for stimulation of T-lymphocytes ${ }^{(28)}$. Since b-hexosaminidase is correlated with histamine release, the authors concluded that the Rhinolight ${ }^{\circledR}$ produced a significant inhibitory effect on histamine release ${ }^{(13)}$. It has been shown that UV-A light significantly inhibited histamine release from 
human basophils and a human mast cell line and that UV-B light had an inhibitory effect only on mast cells. The effect of in vitro UV-A irradiation of basophils is characterized by a biphasic dose-dependent action on histamine release: low doses are followed by a significant inhibitory effect; high doses are followed by histamine liberation ${ }^{(29)}$. The use of Rhinolight ${ }^{\circledR}$, which is characterized by low-dose UV-A and low-dose UV-B, potentially exerts strong inhibitory effect on histamine release. In contrast, Brehmer and Schön ${ }^{(22)}$ reported that monoclonal antibodies to T-lymphocytes and antigen presenting cells in nasal mucosa did not demonstrate significant changes after UV irradiation. The lack of morphological changes or difference in number of cells led the authors of this study to postulate that these cells were either not involved in allergic rhinitis or that the UV dose was too low to evoke any cellular changes. These findings may have wider implications given that some product brochures claim that treatment results in delayed allergic reaction to pollen from reduced mast cell release of histamine.

What is clear however are that UV irradiation of nasal mucosa results in DNA damage and the production of photoproducts. The molecular changes as a consequent of UV exposure have been thoroughly studied in dermatology and are regarded as a precursor to skin cancer ${ }^{(30)}$. In vitro studies have shown that this phenomenon occurs in the nasal mucosa even after one UV irradiation ${ }^{(23)}$. Despite demonstrating cellular regeneration within one week of treatment, it remains uncertain if potential harm exists from regular intranasal treatment since sinonasal symptoms are expected to recur and require further treatment. There is also significant inter-individual variation for damage induction from intranasal treatment suggesting that some may be potentially at risk of developing intranasal cancer. The implications of a rise in malignant melanoma of the nasal cavity cannot be ignored if rhinophototherapy becomes more widely available.

The pathophysiology of sinonasal symptoms is complex involving psychological, physiological and anatomical variables that overlap ${ }^{(31)}$. The clinical benefits of rhinophototherapy, regardless of wavelength, appear to be exclusively symptomatic improvement. Objective measurements of nasal airflow such as acoustic rhinometry and nasal peak flow have not shown any improvement with either red light or UV irradiation ${ }^{(12,13)}$ Furthermore, the expected improvement in inflammation markers following treatment remains equivocal ${ }^{(13,22)}$. It can be argued that these symptomatic improvements represent placebo effect despite several methodologically robust studies with double-blinding ${ }^{(12,13)}$. Controversy certainly abounds on whether medical specialists should accept phototherapy in the armamentarium for treating allergic rhinitis or simply dismiss it completely when asked by patients. Prescribing a placebo treatment remains a contentious issue; some regarding the practice as a virtuous lie but with others it is unethi$\mathrm{cal}^{\left({ }^{32}\right)}$. It is possible that placebo interventions can influence patient-reported outcomes although it is difficult to distinguish patient-reported effects of placebo from biased reporting ${ }^{(33)}$.

\section{CONCLUSION}

The quality of published studies was variable and thus the current strength of recommendation based on the Shekelle et al. ${ }^{(6)}$ system is C (Table 2). Most studies demonstrated symptomatic improvement but not in objective measures such as nasal airflow or inflammatory markers. Treatment does not appear to predispose to carcinogenesis but long-term studies are required to verify this. Intranasal phototherapy may yet prove to be a viable treatment modality for allergic rhinitis but not for nasal polyps. The mechanism of action is not clear and like other CAMS, the placebo effect of phototherapy is not insignificant even in well-designed trials. Although not within the realms of science fiction, more basic science and clinical trials are required before this novel therapy can be regarded as mainstream treatment for allergic rhinitis.

\section{REFERENCES}

1. Passalacqua G, Bousquet PJ, Carlsen KH, et al. ARIA update: I-Systematic review of complementary and alternative medicine for rhinitis and asthma. J Allergy Clin Immunol. 2006; 117: 1054 - 1062.

2. Hunt KJ, Coelho HF, Wider B, et al. Complementary and alternative medicine use in England: results from a national survey. Int $\mathbf{J}$ Clin Pract. 2010; 64: 1496 - 502.

3. Man LX. Complementary and alternative medicine for allergic rhinitis. Curr Opin Otolaryngol Head Neck Surg. 2009; 17: 226 - 231.

4. Kemény L, Koreck A. Ultraviolet light phototherapy for allergic rhinitis. J Photochem Photobiol B. 2007; 87: 58 - 65.

5. Jadad AR, Moore RA, Carroll D, et al. Assessing the quality of reports of randomized clinical trials: is blinding necessary? Control Clin Trials. 1996; 17: $1-12$.

6. Shekelle PG, Woolf SH, Eccles M, Grimshaw J. Clinical guidelines: developing guidelines. BMJ. 1999; 318: 593 - 6 .

7. $\mathrm{Hu} \mathrm{KH}, \mathrm{Li}$ WT. Clinical effects of far-infrared therapy in patients with allergic rhinitis. Conf Proc IEEE Eng Med Biol Soc. 2007; 2007: 1479 - 1482 .

8. Hu KH, Yan DN, Li WT. Effects of phototherapy to Shangyingxiang Xue on patients with allergic rhinitis. 13th International Conference on Biomedical Engineering IFMBE Proceedings. 2009; 23: 992 - 995.

9. McKean S, Vaidyanathan S, Gardiner Q. Intranasal phototherapy for allergic rhinitis. Cochrane Database of Systematic Reviews 2010, Issue 5. Art. No.: CD008513. DOI: 10.1002/14651858. CD008513.

10. Koreck A, Bella Z, Kadocsa E, et al. Intranasal PUVA phototherapy in nasal polyposis--a pilot study. Roum Arch Microbiol Immunol. 2010; 69: 20-23.

11. Neuman I, Finkelstein Y. Narrow-band red light phototherapy in perennial allergic rhinitis and nasal polyposis. Ann Allergy Asthma Immunol. 1997; 78: 399 - 406.

12. Emberlin JC, Lewis RA. Pollen challenge study of a phototherapy device for reducing the symptoms of hay fever. Curr Med Res Opin. 2009; 25: $1635-1644$.

13. Koreck AI, Csoma Z, Bodai L, et al. Rhinophototherapy: a new therapeutic tool for the management of allergic rhinitis. J Allergy Clin Immunol. 2005; 115: $541-547$.

14. Cingi C, Yaz A, Cakli H, Ozudogru E, Kecik C, Bal C. The effects of phototherapy on quality of life in allergic rhinitis cases. Eur Arch Otorhinolaryngol. 2009; 266: 1903 - 1908.

15. Cingi C, Cakli H, Yaz A, Songu M, Bal C. Phototherapy for allergic rhinitis: a prospective, randomized, single-blind, placebocontrolled study. Ther Adv Respir Dis. 2010; 4: 209 - 213.

16. Garaczi E, Boros-Gyevi M, Bella Z, Csoma Z, Kemény L, Koreck A. Intranasal phototherapy is more effective than fexofenadine hydrochloride in the treatment of seasonal allergic rhinitis: results of a pilot study. Photochem Photobiol. 2011; 87: 474 - 477.

17. Csoma Z, Ignacz F, Bor Z, et al. Intranasal irradiation with the xenon chloride ultraviolet $\mathrm{B}$ laser improves allergic rhinitis. J 
Photochem Photobiol B. 2004; 75: 137 - 144.

18. Csoma Z, Koreck A, Ignacz F, et al. PUVA treatment of the nasal cavity improves the clinical symptoms of allergic rhinitis and inhibits the immediate-type hypersensitivity reaction in the skin. $\mathrm{J}$ Photochem Photobiol B. 2006; 83: $21-26$.

19. Bella Z, Kadocsa E, Kemény L, Koreck A. Narrow-band UVB phototherapy of nasal polyps: results of a pilot study. J Photochem Photobiol B. 2010; 100: 123 - 127.

20. Brehmer D. Endonasal phototherapy with Rhinolight for the treatment of allergic rhinitis. Expert Rev Med Devices. 2010; 7: $21-26$.

21. Koreck A, Szechenyi A, Morocz M, et al. Effects of intranasal phototherapy on nasal mucosa in patients with allergic rhinitis. J Photochem Photobiol B. 2007; 89: 163 - 169.

22. Brehmer D, Schön MP. Endonasal phototherapy significantly alleviates symptoms of allergic rhinitis, but has a limited impact on the nasal mucosal immune cells. Eur Arch Otorhinolaryngol. 2011; 268: $393-399$

23. Mitchell D, Paniker L, Sanchez G, et al. Molecular response of nasal mucosa to therapeutic exposure to broad-band ultraviolet radiation. J Cell Mol Med. 2010; 14: 313 - 322.

24. Smith EV, Grindlay DJ, Williams HC. What's new in acne? An analysis of systematic reviews published in $2009-2010$. Clin Exp Dermatol 2011; 36: 119 - 122.

25. Sakamoto FH, Lopes JD, Anderson RR. Photodynamic therapy for acne vulgaris: a critical review from basics to clinical practice: part I. acne vulgaris: when and why consider photodynamic therapy? J Am Acad Dermatol. 2010; 63: 183 - 193.

26. Chen K, Chang BZ, Ju M, Zhang XH, Gu H. Comparative study of photodynamic therapy vs $\mathrm{CO} 2$ laser vaporization in treatment of condylomata acuminata: a randomized clinical trial. Br J Dermatol. 2007; 156: 516 - 520 .
27. Gao X, Xing D. Molecular mechanisms of cell proliferation induced by low power laser irradiation. J Biomed Sci. 2009; 16: 4.

28. Mygind N, Nielsen LP, Hoffmann HJ, et al. Mode of action of intranasal corticosteroids. J Allergy Clin Immunol. 2001; 108; S16-25.

29. Kemény L, Koreck A. Ultraviolet light phototherapy for allergic rhinitis. J Photochem Photobiol B. 2007; 87: 58 - 65.

30. Marrot L, Meunier JR. Skin DNA photodamage and its biological consequences. J Am Acad Dermatol. 2008; 58: S139 - 148.

31. Eccles R. Pathophysiology of nasal symptoms. Am J Rhinol. 2000; 14: $335-338$.

32. Tilburt JC, Emanuel EJ, Kaptchuk TJ, Curlin FA, Miller FG. Prescribing "placebo treatments": results of national survey of US internists and rheumatologists. BMJ. 2008; 337: a1938.

33. Hróbjartsson A, Gøtzsche PC. Placebo interventions for all clinical conditions. Cochrane Database Syst Rev. 2010; 1: CD003974.

Mr. Samuel C. Leong MPhil

Department of Otorhinolaryngology -

Head and Neck Surgery

Royal Liverpool and Broadgreen University Hospitals NHS Trust

Liverpool L7 8XP

United Kingdom

Fax: +44-779-596 3905

E-mail: lcheel@doctors.org.uk

\section{ADVERTISEMENT}

\begin{tabular}{|c|c|}
\hline 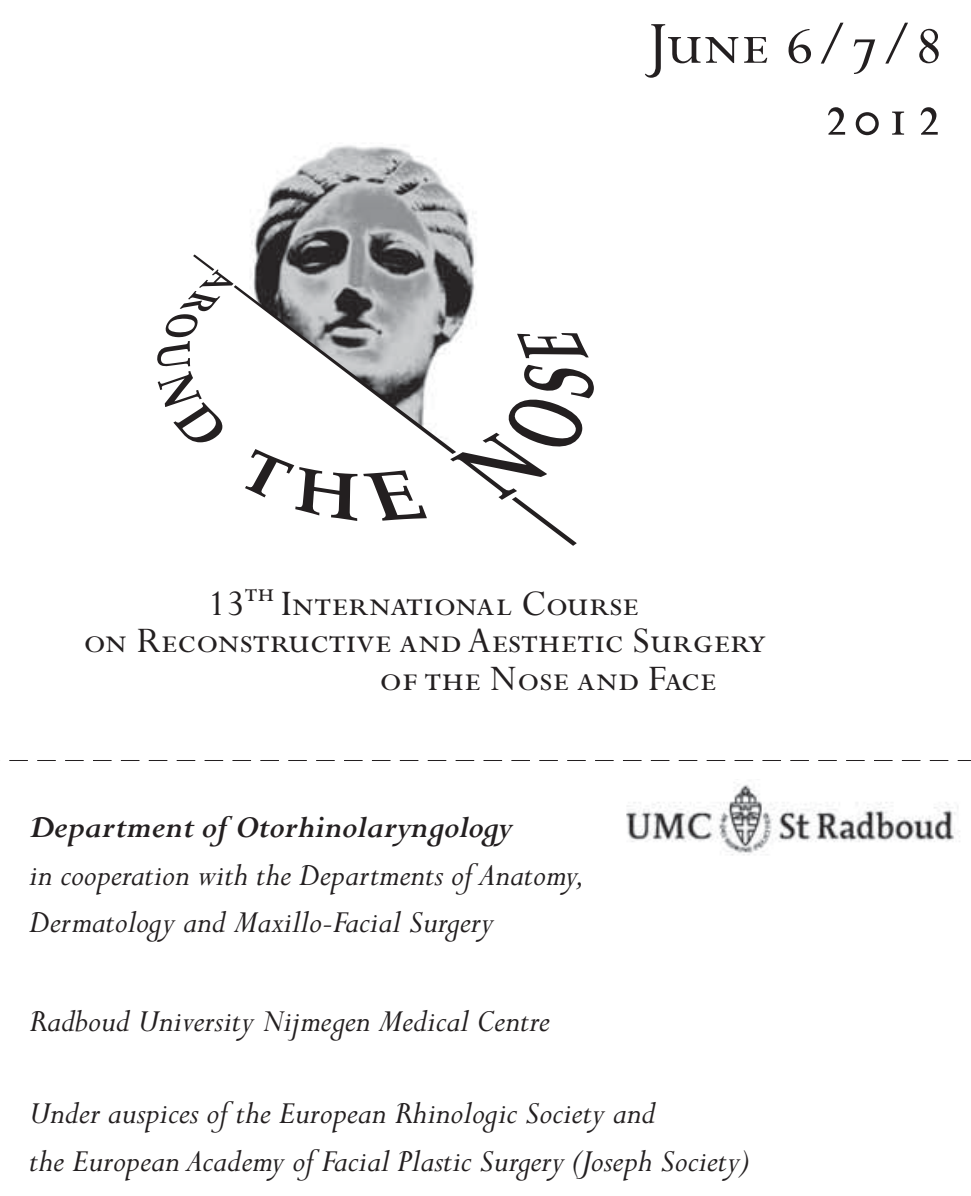 & $\begin{array}{l}\text { External rhinoplasty } \\
\text { Transposition flaps and vascularized flaps } \\
\text { Nasal reconstruction } \\
\text { Otoplasty } \\
\text { Blepharoplasty } \\
\text { Mentoplasty } \\
\text { Rhytidoplasty } \\
\text { Techniques mentioned above are explained } \\
\text { step by step by a multidisciplinary international } \\
\text { faculty of experts. After each presentation a } \\
\text { technique is practised hands on. Instead of } \\
\text { employing chemicals to preserve cadavers, they } \\
\text { are frozen and brought to room temperature, } \\
\text { providing the feel and texture of facial soft tissue. }\end{array}$ \\
\hline
\end{tabular}

